Research Article

\title{
Cyanidin-Based Novel Organic Sensitizer for Efficient Dye-Sensitized Solar Cells: DFT/TDDFT Study
}

\author{
Kalpana Galappaththi, ${ }^{1}$ Andery Lim, ${ }^{2}$ Piyasiri Ekanayake, ${ }^{1,2}$ and \\ Mohammad Iskandar Petra ${ }^{3}$ \\ ${ }^{1}$ Applied Physics Program, Faculty of Sciences, Universiti Brunei Darussalam, Jalan Tungku Link, Gadong BE1410, \\ Brunei Darussalam \\ ${ }^{2}$ Physical and Geological Sciences Programme, Centre for Advanced Material and Energy Sciences, Universiti Brunei Darussalam, \\ Jalan Tungku Link, Gadong BE1410, Brunei Darussalam \\ ${ }^{3}$ Faculty of Integrated Technology, Universiti Brunei Darussalam, Jalan Tungku Link, Gadong BE1410, Brunei Darussalam
}

Correspondence should be addressed to Piyasiri Ekanayake; piyasiri.ekanayake@ubd.edu.bn

Received 28 April 2017; Accepted 20 July 2017; Published 30 August 2017

Academic Editor: Polycarpos Falaras

Copyright (c) 2017 Kalpana Galappaththi et al. This is an open access article distributed under the Creative Commons Attribution License, which permits unrestricted use, distribution, and reproduction in any medium, provided the original work is properly cited.

\begin{abstract}
Cyanidin is widely considered as a potential natural sensitizer in dye-sensitized solar cells due to its promising electron-donating and electron-accepting abilities and cheap availability. We consider modifications of cyanidin structure in order to obtain broader UV-Vis absorption and hence to achieve better performance in DSSC. The modified molecule consists of cyanidin and the benzothiadiazolylbenzoic acid group, where the benzothiadiazolylbenzoic acid group is attached to the cyanidin molecule by replacing one hydroxyl group. The resulting structure was then computationally simulated by using the Spartan'10 software package. The molecular geometries, electronic structures, absorption spectra, and electron injections of the newly designed organic sensitizer were investigated in this work through density functional theory (DFT) and time-dependent density functional theory (TDDFT) calculations using the Gaussian'09W software package. Furthermore, TDDFT computational calculations were performed on cyanadin and benzothiadiazolylbenzoic acid separately, as reference. The computational studies on the new sensitizer have shown a reduced HOMO-LUMO gap; bathochromic and hyperchromic shifts of absorption spectra range up to near-infrared region revealing its enhanced ability to sensitize DSSCs.
\end{abstract}

\section{Introduction}

Dye-sensitized solar cells (DSSC), first introduced in 1991, are emerging as the most promising alternative to traditional silicon solar cells due to the low cost of fabrication and easy manufacturing process [1-4]. The sensitizer, which plays a major role in DSSC function, absorbs light and injects electrons to the conduction band of $\mathrm{TiO}_{2}$ from its excited state. Sensitizers based on ruthenium $[5,6]$, zinc porphyrin $[7,8]$, and organic dyes [9] have been discovered and applied as efficient sensitizers for DSSC. Despite of the high efficiency of ruthenium and porphyrin sensitizers, environmental complication and sophisticated synthesizing procedures make it necessary to find for alternative efficient sensitizers.
Presently, many efforts are created to develop novel, reliable, efficient, and environmental-friendly sensitizers for real-world applications $[5,10,11]$.

Natural dye molecules such as flavonoids, betalains, carotenoids, and chlorophylls are currently being tested as alternatives to the expensive sensitizers in the fabrication of DSSC, considering their electron-donating and electronaccepting abilities [12-16]. However, the efficiencies of DSSCs sensitized with natural dyes are still very poor, mainly due to the poor light-harvesting properties associated with them [17-20]. Therefore, the need to invent natural dyebased new dye with improved optical properties favorable to enhance efficiency of DSSC is a worthy solution.

In this study, a cyanidin, which belongs to flavonoids, based new organic dye is modeled and its suitability as a 
<smiles>Oc1cc(O)c2cc(O)c(-c3ccc(O)c(O)c3)[o+]c2c1</smiles>

Cyanidin<smiles>O=C(O)c1ccc(-c2cccc3nsnc23)cc1</smiles>

Benzothiadiazolylbenzoic acid $(B T B A)$

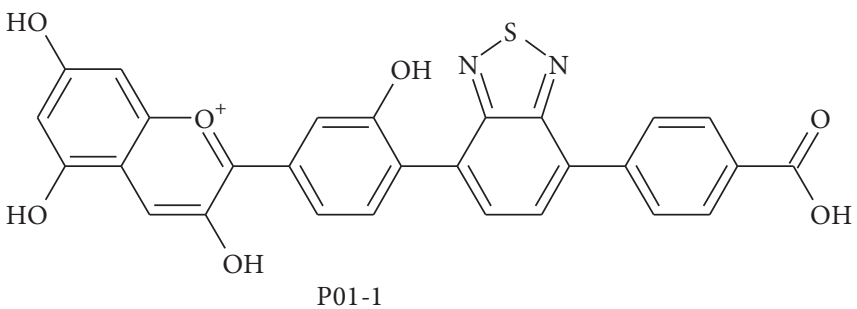

FIgURE 1: Fundamental molecular structure of cyanidin, BTBA, and P01-1.

novel sensitizer in DSSC is computationally tested using density functional theory (DFT) and time-dependent density functional theory (TDDFT) calculations. The new sensitizer, $P 01-1$, is designed by attaching one of the hydroxyl groups on the benzene ring of cyanidin to the benzothiadiazolylbenzoic acid $(B T B A)$ unit as shown in Figure 1. Following IUPAC rules, we have named the molecule $(P 01-1)$ as $\mathrm{p}-\{5-[2-$ hydroxy-4-(3,5,7-trihydroxy-2-chromenyl)phenyl]-8-thia-7, 9-diazabicyclo[4.3.0]nona-1(9),2,4,6-tetraen-2-yl\}benzoic acid. In the design, we used benzothiadiazolylbenzoic acid as an electron acceptor by considering its strong electron withdrawing ability in some excellent dyes reported by Yao and coworkers [21]. The position of the BTBA substitution to cyanidin is based on our previous work [12]; TDDFT calculations of cyanidin revealed that the electron density cloud of the lowest unoccupied molecular orbital (LUMO) is highly localized and denser in the selected hydroxyl group.

\section{Computational Details}

The molecular structures of P01-1, cyanidin, and benzothiadiazolylbenzoic acid (BTBA) are computed using Spartan'10 software [22] to retrieve the molecular geometry coordinates. Both DFT and TDDFT calculations are performed using Gaussian'09W software [23]. The molecular structures of P01-1, cyanidin, and BTBA are fully optimized using Becke's three-parameter hybrid functional using Lee-Yang-Parr hybrid functional (B3LYP) [24] in ethanol. The electronic structures and total energies are calculated using 6-31g (d) basis set which adopted to describe metal-free atoms. All of the calculations include the solvation effect in ethanol using the polarizable continuum model (PCM) [25]. The lowest 5 singlet-singlet excitations are included in the TDDFT calculations. The models of electron density of various energy levels of the P01-1 are visualized, and absorption spectra of
TABLE 1: Summary of DFT computational calculation of cyanidin, $B T B A$, and P01-1 constituents in ethanol with geometry optimization.

\begin{tabular}{lccc}
\hline \multirow{2}{*}{ Sensitizer } & \multicolumn{3}{c}{ With geometry optimization } \\
& HOMO $(\mathrm{eV})$ & LUMO $(\mathrm{eV})$ & Energy gap $(\mathrm{eV})$ \\
\hline Cyanidin & -6.18 & -3.39 & 2.79 \\
BTBA & -6.33 & -2.55 & 3.78 \\
P01-1 & -6.18 & -3.66 & 2.52 \\
\hline
\end{tabular}

P01-1, cyanidin, and BTBA are simulated using GaussView version 5.0 [26].

The synthetic strategy to reach $P 01-1$ is by coupling cyanidin and bromo-benzothiadiazolylbenzoic acid together via Ullmann cross coupling reaction [27, 28]. Cyanidin can be extracted from natural flowers and fruits; benzothiadiazolylbenzoic acid (BTBA) can be synthesized by following a procedure reported by Yao and coworkers [21].

\section{Results and Discussion}

3.1. DFT Calculation. DFT calculations are performed on the P01-1 molecule with a solvent effect on ethanol. For comparative purposes, we also performed calculations on cyanidin and $B T B A$. The results are summarized in Table 1 . It is observed that the band gap value of P01-1, obtained after geometry optimization in ethanol, is smaller than HOMOLUMO gap values of cyanidin and BTBA in ethanol.

3.2. HOMO-LUMO Energy Levels. Molecular orbitals and their properties such as corresponding energy are very useful to identify the best sensitizers for DSSCs. The highest occupied molecular orbital (HOMO) represents a donating ability of electrons; LUMO represents acceptability of electrons. For the efficient electron injection and regeneration 
TABle 2: Computed excitation energies in $(\mathrm{eV}),(\mathrm{nm})$, and the oscillator strength (f) of the cyanidin and P01-1 obtained by TDDFT calculations at B3LYP/6-31g (d) level with the inclusion of geometry optimization under the solvation effect of ethanol.

\begin{tabular}{|c|c|c|c|c|}
\hline \multirow{3}{*}{ Sensitizer } & \multicolumn{4}{|c|}{ Optimized in ethanol } \\
\hline & \multicolumn{2}{|c|}{$\begin{array}{c}\text { Calculated } \\
\text { energy }\end{array}$} & \multirow{2}{*}{$\begin{array}{l}\text { Oscillator strength } \\
\text { (f) }\end{array}$} & \multirow{2}{*}{ 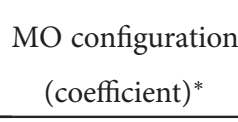 } \\
\hline & $(\mathrm{eV})$ & $(\mathrm{nm})$ & & \\
\hline \multirow{9}{*}{ Cyanidin } & 2.52 & 492.16 & 0.583 & $\mathrm{H} \rightarrow \mathrm{L}=0.695$ \\
\hline & 2.82 & 439.86 & 0.010 & $\mathrm{H}-3 \rightarrow \mathrm{L}=0.318$ \\
\hline & & & & $\mathrm{H}-2 \rightarrow \mathrm{L}=0.467$ \\
\hline & & & & $\mathrm{H} \rightarrow \mathrm{L}+1=0.211$ \\
\hline & 3.17 & 391.21 & 0.273 & $\mathrm{H}-3 \rightarrow \mathrm{L}=0.322$ \\
\hline & & & & $\mathrm{H}-2 \rightarrow \mathrm{L}=0.192$ \\
\hline & & & & $\mathrm{H}-1 \rightarrow \mathrm{L}=0.586$ \\
\hline & 3.88 & 319.36 & 0.025 & $\mathrm{H}-4 \rightarrow \mathrm{L}=0.687$ \\
\hline & 4.49 & 276 & 0.055 & $\mathrm{H}-3 \rightarrow \mathrm{L}=0.516$ \\
\hline \multirow{8}{*}{ P01-1 } & 2.18 & 567.75 & 0.795 & $\mathrm{H} \rightarrow \mathrm{L}=0.703$ \\
\hline & 2.60 & 476.81 & 0.054 & $\mathrm{H}-2 \rightarrow \mathrm{L}=0.132$ \\
\hline & & & & $\mathrm{H}-1 \rightarrow \mathrm{L}=0.665$ \\
\hline & 2.79 & 443.99 & 0.007 & $\mathrm{H}-2 \rightarrow \mathrm{L}=0.685$ \\
\hline & 3.00 & 413.81 & 0.312 & $\mathrm{H} \rightarrow \mathrm{L}+1=0.668$ \\
\hline & 3.22 & 385.11 & 0.148 & $\mathrm{H}-4 \rightarrow \mathrm{L}=0.613$ \\
\hline & & & & $\mathrm{H}-1 \rightarrow \mathrm{L}=0.194$ \\
\hline & & & & $\mathrm{H} \rightarrow \mathrm{L}+1=0.187$ \\
\hline
\end{tabular}

${ }^{*}$ Molecular orbitals with configuration coefficient $<0.1$ are not shown.

processes, LUMO of sensitizer must be above the conduction band edge of $\mathrm{TiO}_{2}(-4.0 \mathrm{eV})$ while $\mathrm{HOMO}$ of sensitizer must be below the energy level of the redox couple $(-4.8 \mathrm{eV})$ [29-31]. The DFT calculations (see Table 1) show that the P01-1 satisfies the conditions for efficient photo-energy conversion.

\subsection{TDDFT Calculations and Absorption Spectra. TDDFT} simulations are performed on the newly designed sensitizer P01-1, cyanidin, and BTBA, to gain perceptions on the excitation energy, electronic transition, optical properties, and UV-Vis absorption spectra for the singlet-singlet transition with hybrid functional B3LYP in ethanol solution. The lowest 5 singlet-singlet excitations are included in the TDDFT calculations.

The excitation energies, oscillator strengths, and molar extinction coefficient for the five states of P01-1 and cyanidin calculated using B3LYP on 6-31g (d) basis set are shown in Table 2, and the computer simulated UV-Vis absorption spectra obtained for the P01-1, BTBA, and cyanidin via TDDFT calculations are depicted in Figure 2.

Oscillator strength expresses the strength of transitions to the excited states. The higher the oscillator strength, the higher the possibility for the molecule to be sensitized [32-36]. Except in the third excitation state, all other excitation states up to fifth excitation state have shown that oscillator strengths of P01-1 are higher than those of cyanidin.

P01-1 has produced four significant oscillator strengths up to the fifth excitation states except third excitation state,

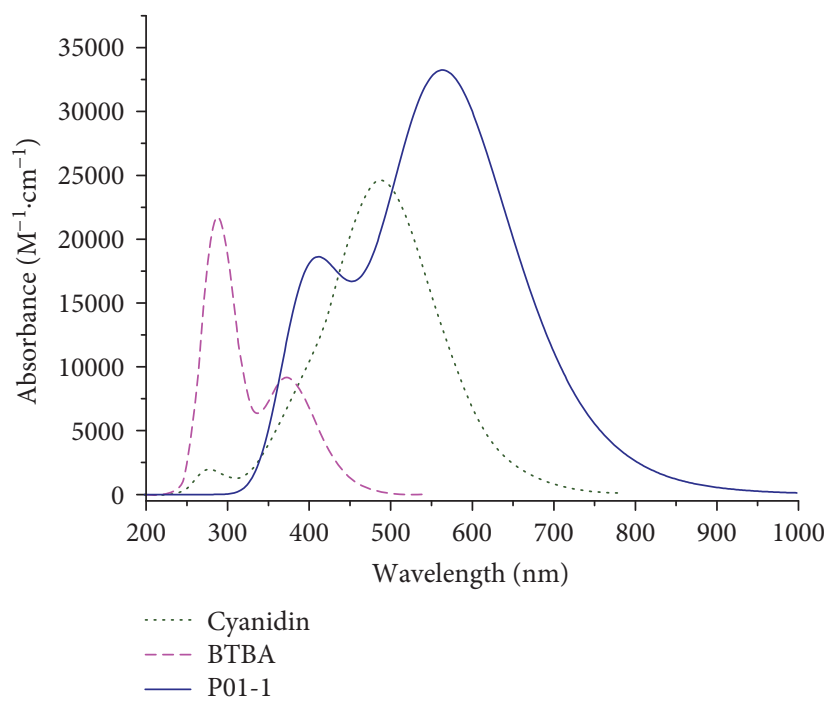

FIgURE 2: UV-Vis absorption spectra obtained for the P01-1, BTBA, and cyanidin via the output of TDDFT calculations with the solvation effect of ethanol solution.

while cyanidin only produced three significant oscillator strengths at the first, third, and fifth excitation states. This suggested that P01-1 has more potential to be sensitized as compared to cyanidin. In addition, the $\lambda_{\max }$ values of the P01-1 at each five excitation states shifted to longer wavelengths compared to $\lambda_{\max }$ of cyanidin by $75.59 \mathrm{~nm}$, $36.95 \mathrm{~nm}, 52.78 \mathrm{~nm}, 94.45 \mathrm{~nm}$, and $109.11 \mathrm{~nm}$, respectively.

The absorption spectra of cyanidin and the BTBA extend only up to $800 \mathrm{~nm}$ and $550 \mathrm{~nm}$. Interestingly, the absorption spectra of the P01-1 have shown a redshift up to near IR of $1000 \mathrm{~nm}$ (Figure 2). The absorption bands of P01-1 are more intense and broad in the visible region. The absorption maxima of P01-1 has bathochromic shifts of $75.59 \mathrm{~nm}$ as compared to that of cyanidin. Furthermore, they have hyperchromic shifts of $8.577\left(10^{3} \mathrm{M}^{-1} \cdot \mathrm{cm}^{-1}\right)$. These shifts in the modified dyes are favorable to effectively lead to an efficient sensitization.

3.4. Molecular Orbitals. The electron density clouds modelled at the transition of various energy levels that correspond to the first five excited states of P01-1 are shown in Figure 3. At different energy levels, it could be observed that electron density clouds are localized in different regions of the P01-1 molecule.

Almost all levels of the ground state energy such as HOMO-4, HOMO-2, HOMO-1, and HOMO levels of P01-1 are $\pi$-type. At the HOMO, HOMO-1, and HOMO-3 levels, the electron density clouds are mostly delocalized over the entire molecule of P01-1 but, at the HOMO-2 level, the electron density cloud is more localized in the benzene ring of the cyanidin unit of P01-1.

In the P01-1 molecule, the electron cloud of LUMO is $\pi^{*}$ type and the molecular orbital is localized at cyanidin unit. Here, the electron density cloud is observed to be denser in a chromenylium unit than the benzene dial on cyanidin unit of P01-1. The photogenerated electrons are excited to 


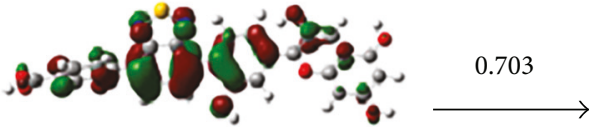

HOMO

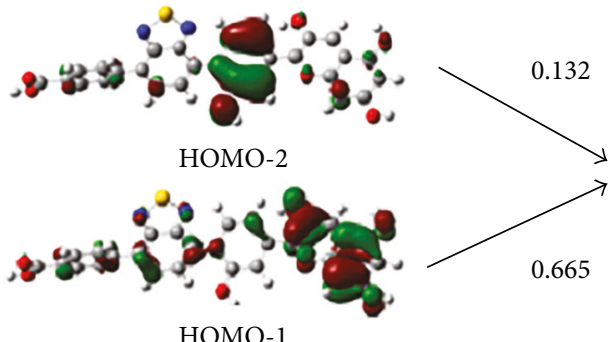

HOMO-1

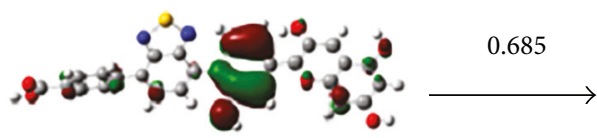

HOMO-2

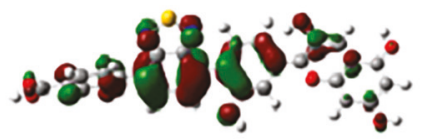

HOMO

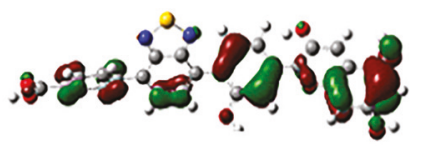

HOMO-4

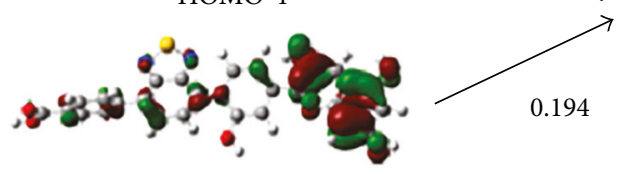

HOMO-1

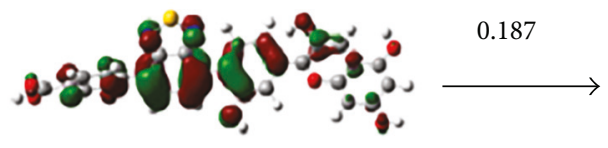

HOMO

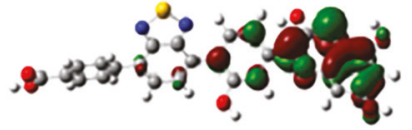

LUMO
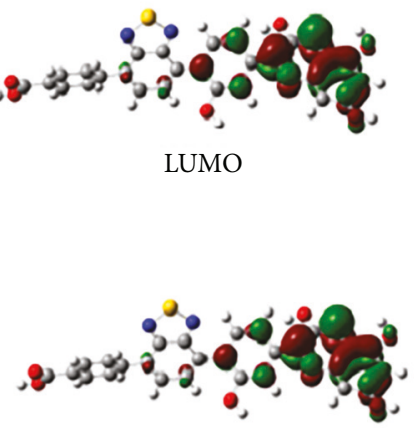

LUMO

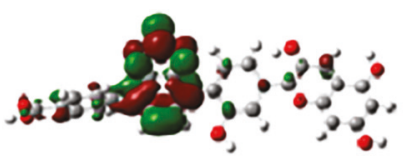

$\mathrm{LUMO}+1$

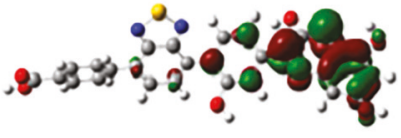

LUMO

FIgURE 3: The behavior of electron density clouds at the various energy levels corresponding to the first five excited states of P01-1 in ethanol using the TDDFT simulation with isovalue of contour $=0.03$.

chromenylium unit on the electrode of $\mathrm{TiO}_{2}$. Subsequently, electrons are easily injected into the conduction band of $\mathrm{TiO}_{2}$ [32]. This electron injection is most possible from the chromenylium unit as it has denser electron density cloud in the LUMO $\pi^{*}$ state. Therefore, the anchoring group of P01-1 molecule that may efficiently inject electrons into the $\mathrm{TiO}_{2}$ is deduced to be the hydroxyl group.

\section{Conclusions}

The molecular geometries, electronic structures, and absorption spectra of the newly designed molecules of the P01-1 sensitizer are investigated by DFT and TDDFT computational analyses. By evaluating HOMO and LUMO energy levels obtained from DFT calculations of geometryoptimized structure of P01-1 molecules with solvent effect in ethanol, P01-1 satisfied the main requirement for efficient electron injection, where the LUMO level of P01-1 is higher than the conduction band of the $\mathrm{TiO}_{2}$ and the HOMO level of P01-1 is sufficiently lower than the redox couple. Furthermore, the band gap of P01-1 is smaller than that of cyanidin and $B T B A$ in ethanol.

The UV-Vis absorption spectra reveal that the P01-1 complex extends absorption spectra from $800 \mathrm{~nm}$ to $1000 \mathrm{~nm}$ range with bathochromic and hyperchromic shifts. All these results suggest a more promising sensitization ability of P01-1 which is designed by modifying the sensitizer, cyanidin. 


\section{Disclosure}

Kalpana Galappaththi permanent address is Institute of Technology University of Moratuwa, University of Moratuwa, Katubedda, Sri Lanka.

\section{Conflicts of Interest}

The authors declare that there is no conflict of interests regarding the publication of this paper.

\section{Acknowledgments}

Kalpana Galappaththi acknowledges Graduate Research Scholarship (GRS) from Universiti Brunei Darussalam.

\section{References}

[1] M. Grätzel, "Recent advances in sensitized mesoscopic solar cells," Accounts of Chemical Research, vol. 42, pp. 1788-1798, 2009.

[2] B. O’Regan and M. Grätzel, "A low-cost, high-efficiency solar cell based on dye-sensitized colloidal TiO2 films," Nature, vol. 353, pp. 737-740, 1991.

[3] M. Grätzel, "Photoelectrochemical cells," Nature, vol. 414, pp. 338-344, 2001.

[4] Z. Arifin, S. Soeparman, D. Widhiyanuriyawan, and S. Suyitno, "Performance enhancement of dye-sensitized solar cells using a natural sensitizer," International Journal of Photoenergy, vol. 2017, Article ID 2704864, 5 pages, 2017.

[5] M. Grätzel, "Solar energy conversion by dye-sensitized photovoltaic cells," Inorganic Chemistry, vol. 44, pp. 6841-6851, 2005.

[6] S. Fantacci, F. De Angelis, A. Sgamellotti, and N. Re, "A TDDFT study of the ruthenium(II) polyazaaromatic complex $[\mathrm{Ru}(\mathrm{dppz})(\mathrm{phen}) 2] 2+$ in solution," Chemical Physics Letters, vol. 396, pp. 43-48, 2004.

[7] X.-F. Wang, H. Tamiaki, S. Caramori et al., "Cyclic tetrapyrrole based molecules for dye-sensitized solar cells," Energy \& Environmental Science, vol. 3, pp. 94-106, 2010.

[8] H. Dong, X. Zhou, and C. Jiang, "Molecular design and theoretical investigation on novel porphyrin derivatives for dye-sensitized solar cells," Theoretical Chemistry Accounts, vol. 131, p. 1102, 2012.

[9] C. Baldoli, S. Bertuolo, E. Licandro et al., "Benzodithiophene based organic dyes for DSSC: effect of alkyl chain substitution on dye efficiency," Dyes and Pigments, vol. 121, pp. 351-362, 2015.

[10] M. L. Parisi, S. Maranghi, and R. Basosi, "The evolution of the dye sensitized solar cells from Grätzel prototype to up-scaled solar applications: a life cycle assessment approach," Renewable and Sustainable Energy Reviews, vol. 39, pp. 124-138, 2014.

[11] V. S. Manthou, D. Pergant, G. Rotas, P. Falaras, and G. C. Vougioukalakis, "5-Alkyl-8-hydroxyquinolines: synthesis and application in dye-sensitized solar cells," Synlett, vol. 28, pp. 929-933, 2017.

[12] P. Ekanayake, M. R. R. Kooh, N. T. R. N. Kumara et al., "Combined experimental and DFT-TDDFT study of photo-active constituents of Canarium odontophyllum for DSSC application," Chemical Physics Letters, vol. 585, pp. 121-127, 2013.
[13] A. Lim, D. N. F. B. Pg Damit, and P. Ekanayake, "Tailoring of extraction solvent of Ixora coccinea flower to enhance charge transport properties in dye-sensitized solar cells," Ionics (Kiel), vol. 21, pp. 2897-2904, 2015.

[14] M. R. Narayan, "Review: dye sensitized solar cells based on natural photosensitizers," Renewable and Sustainable Energy Reviews, vol. 16, pp. 208-215, 2012.

[15] K. Tennakone, A. R. Kumarasinghe, G. R. R. A. Kumara, K. G. U. Wijayantha, and P. M. Sirimanne, "Nanoporous $\mathrm{TiO} 2$ photoanode sensitized with the flower pigment cyanidin," Journal of Photochemistry and Photobiology A: Chemistry, vol. 108, pp. 193-195, 1997.

[16] M. H. Buraidah, L. P. Teo, S. N. F. Yusuf et al., " $\mathrm{TiO}_{2} /$ chitosan- $\mathrm{NH}_{4} \mathrm{I}\left(+\mathrm{I}_{2}\right)$-BMII-based dye-sensitized solar cells with anthocyanin dyes extracted from black rice and red cabbage," International Journal of Photoenergy, vol. 2011, Article ID 273683, 11 pages, 2011.

[17] A. Polo and N. Murakamiiha, "Blue sensitizers for solar cells: natural dyes from Calafate and Jaboticaba," Solar Energy Materials \& Solar Cells, vol. 90, pp. 1936-1944, 2006.

[18] K. Wongcharee, V. Meeyoo, and S. Chavadej, "Dye-sensitized solar cell using natural dyes extracted from rosella and blue pea flowers," Solar Energy Materials \& Solar Cells, vol. 91, pp. 566-571, 2007.

[19] A. Lim, N. T. R. N. Kumara, A. L. Tan et al., "Potential natural sensitizers extracted from the skin of Canarium odontophyllum fruits for dye-sensitized solar cells," Spectrochimica Acta Part A: Molecular and Biomolecular Spectroscopy, vol. 138, pp. 596-602, 2015.

[20] A. Lim, N. Haji Manaf, K. Tennakoon et al., "Higher performance of DSSC with dyes from Cladophora sp. as mixed Cosensitizer through synergistic effect," Journal of Biophysics, vol. 2015, Article ID 510467, 8 pages, 2015.

[21] Z. Yao, M. Zhang, H. Wu, L. Yang, R. Li, and P. Wang, "Donor/acceptor indenoperylene dye for highly efficient organic dye-sensitized solar cells," Journal of the American Chemical Society, vol. 137, pp. 3799-3802, 2015.

[22] B. Deppmeier, A. Driessen, T. Hehre et al., Spartan'10, Wavefunction, 2011.

[23] M. J. Frisch, G. W. Trucks, H. B. Schlegel et al., Gaussian 09, Revision C.01, Gaussian, Wallingford, CT, USA, 2010.

[24] C. Lee, W. Yang, and R. G. Parr, "Development of the Colle-Salvetti correlation-energy formula into a functional of the electron density," Physical Review B, vol. 37, pp. 785-789, 1988.

[25] J. Tomasi, B. Mennucci, and R. Cammi, "Quantum mechanical continuum solvation models," Chemical Reviews, vol. 105, pp. 2999-3093, 2005.

[26] R. Dennington, T. Keith, and J. Millam, GaussView, Version 5, Semichem, Shawnee Mission, KS, USA, 2009.

[27] Z. Wang, "Ullmann Coupling," in Comprehensive Organic Name Reactions and Reagents, John Wiley \& Sons, Inc., Hoboken, NJ, USA, 2010.

[28] R. Q. Brewster, T. Groening, R. Q. Brewster, and T. Groening, " $p$-Nitrodiphenyl ether," in Organic Syntheses, p. 66, John Wiley \& Sons, Inc., Hoboken, NJ, USA, 2003.

[29] D. N. F. P. Damit, K. Galappaththi, A. Lim, M. I. Petra, and P. Ekanayake, "Formulation of water to ethanol ratio as extraction solvents of Ixora coccinea and Bougainvillea glabra and their effect on dye aggregation in relation to DSSC performance," Ionics (Kiel), vol. 23, pp. 485-495, 2017. 
[30] B. Basheer, D. Mathew, B. K. George, and C. P. Reghunadhan Nair, "An overview on the spectrum of sensitizers: the heart of dye sensitized solar cells," Solar Energy, vol. 108, pp. 479-507, 2014.

[31] B.-G. Kim, K. Chung, and J. Kim, "Molecular design principle of all-organic dyes for dye-sensitized solar cells," Chemistry-A European Journal, vol. 19, pp. 5220-5230, 2013.

[32] K. Galappaththi, P. Ekanayake, and M. I. Petra, "Computational study of modification of cyanidin as high efficient organic sensitizer for dye sensitized solar cells," Scientia Bruneiana, vol. 15, 2016.

[33] F. De Angelis, S. Fantacci, A. Selloni, M. K. Nazeeruddin, and M. Grätzel, "Time-dependent density functional theory investigations on the excited states of $\mathrm{Ru}(\mathrm{II})$-dye-sensitized $\mathrm{TiO} 2$ nanoparticles: the role of sensitizer protonation," Journal of the American Chemical Society, vol. 129, 2007.

[34] N. T. R. N. Kumara, M. R. R. Kooh, A. Lim et al., "DFT/ TDDFT and experimental studies of natural pigments extracted from black tea waste for DSSC application," International Journal of Photoenergy, vol. 2013, Article ID 109843, 8 pages, 2013.

[35] F. De Angelis, S. Fantacci, A. Selloni, M. K. Nazeeruddin, and M. Grätzel, "First-principles modeling of the adsorption geometry and electronic structure of $\mathrm{Ru}(\mathrm{II})$ dyes on extended $\mathrm{TiO}_{2}$ substrates for dye-sensitized solar cell applications," Journal of Physical Chemistry C, vol. 114, pp. 6054-6061, 2010.

[36] L.-J. He, J. Chen, F.-Q. Bai, R. Jia, J. Wang, and H.-X. Zhang, "Fine-tuning $\pi$-spacer for high efficiency performance DSSC: a theoretical exploration with D $-\pi-$ A based organic dye," Dyes and Pigments, vol. 141, pp. 251-261, 2017. 

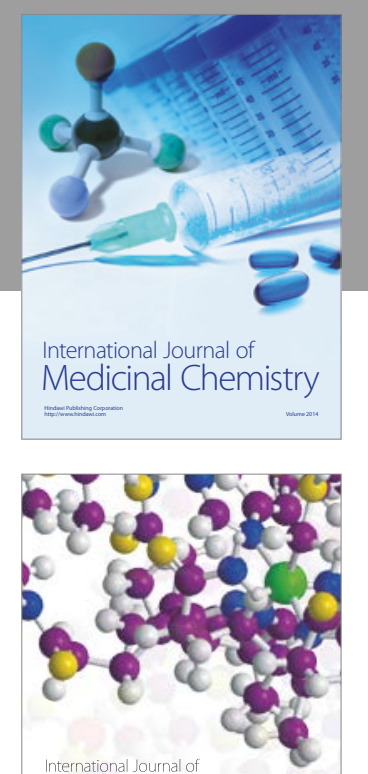

Carbohydrate Chemistry

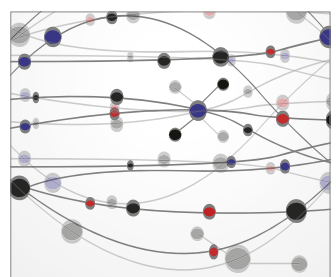

The Scientific World Journal
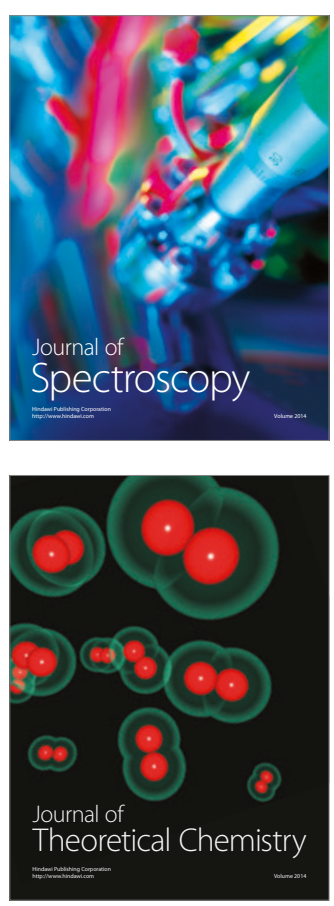
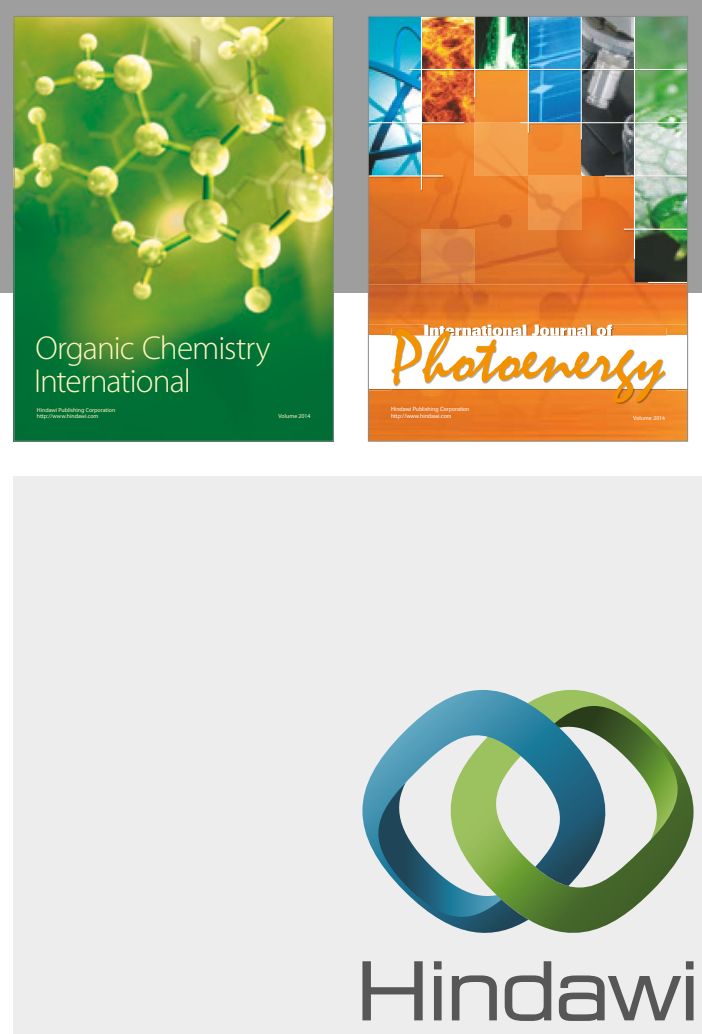

Submit your manuscripts at

https://www.hindawi.com

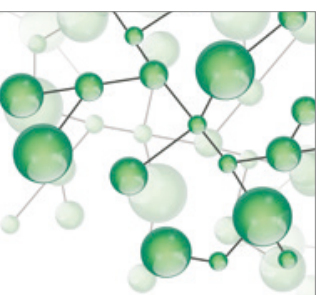

International Journal of

Inorganic Chemistry

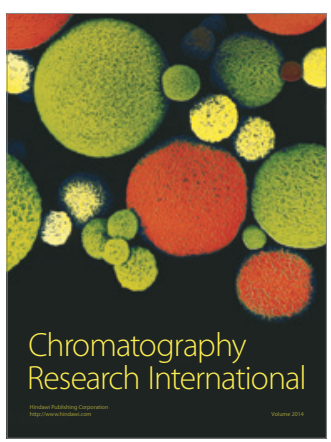

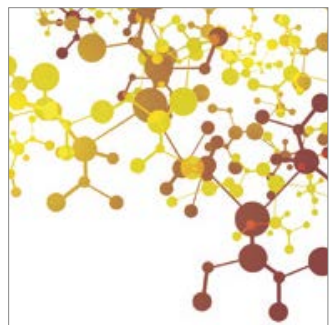

Applied Chemistry
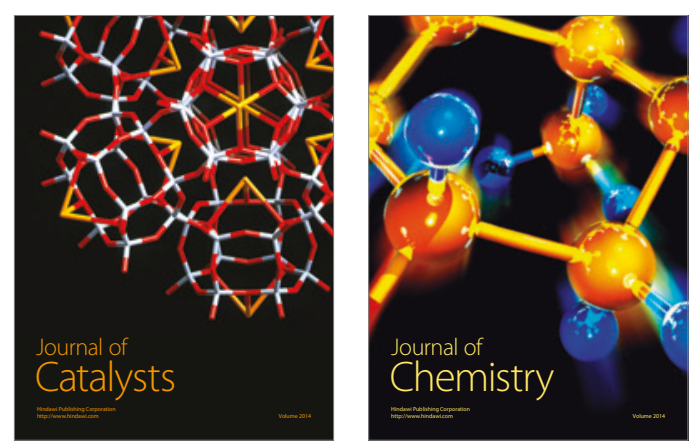
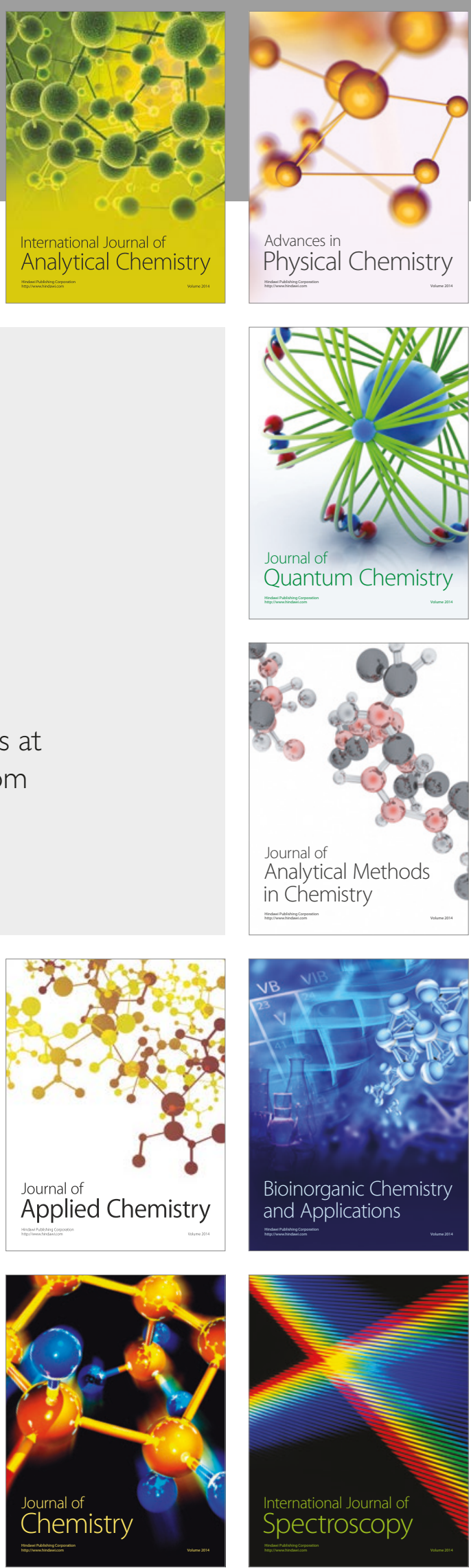